Thorax (1954), 9, 14.

\title{
EBSTEIN'S DISEASE
}

\author{
BY \\ W. E. MEDD, M. B. MATTHEWS, AND W. R. R. THURSFIELD \\ From the Cardiac and X-ray Departments, St. Thomas's Hospital, London
}

(RECEIVED FOR PUBLICATION MAY 15,1953 )

A case of Ebstein's malformation of the tricuspid valve is described. The clinical diagnosis and the findings at angiocardiography and cardiac catheterization are reviewed in all the cases published since 1948.

\section{CAse History}

Linda B. was born in September, 1946. Delivery was normal and her mother had been well during pregnancy. She was first seen at St. Thomas's Hospital in January, 1947, when aged 4 months. There was a history of vomiting for one week attributed to a mild attack of gastro-enteritis. A systolic murmur was heard over the praecordium, but cyanosis was not noted. At the age of 2 years the child was an inpatient with severe stomatitis; comments at the time included that she had a red face and a red tongue, and one observer recorded "a reduplicated apical second sound." In January, 1953, when aged $6 \frac{1}{2}$ years she was re-admitted with the following history. She had had a cough, fever, and abdominal pain for the previous 24 hours. This settled rapidly. But she was seen to be cyanosed, and on direct questioning her father said that the child would never hurry and became blue if she tried to do so. He had noticed this for the previous two to three years. She also squatted when tired.

She was a red-haired, normally developed girl (weight, 2 st. $4 \mathrm{lb}$.; height, $3 \mathrm{ft} 5 \mathrm{in}$.). The abnormalities were confined to the cardiovascular system. There was moderate central cyanosis and the fingers and toes were clubbed. The pulse was regular $(90$ per minute). The blood pressure was $100 / 75 \mathrm{~mm}$. $\mathrm{Hg}$. Jugular venous pulsation was visible in the neck, but the pressure was not raised and its form was normal. The right side of the chest was slightly prominent. The apex beat was in the fifth space in the anterior axillary line. There was no right ventricular impulse to the left of the sternum. The most obvious auscultatory finding was a triple rhythm. The added sound occurred at about the time of a third heart sound, and was loudest in the fourth left space parasternally where it was as loud as the first sound. There was a moderately loud systolic murmur maximal at the same site, accompanied, in full expiration, by a slight thrill. There was no diastolic murmur.
A radiograph showed that the heart shadow was considerably enlarged to the right and left, and the borders showed an even contour. On radioscopy there was a marked outward pulsation of the right border during systole. On the left border pulsation was confined to the lower third, and was inward during systole. In the left anterior oblique position $\left(60^{\circ}\right)$ the right auricle was enlarged and the posterior border of the heart overlapped the spine. The pulmonary vascular markings were diminished.

An electrocardiogram (Fig. 2) showed that the P.R. interval was $0.24 \mathrm{sec}$. There was a complete right bundle branch block, the form of which was unusual in that both primary and secondary $R$. waves were small in $V_{1}, V_{2}$, and $V_{3}$.

The blood count showed $\mathrm{Hb} 118 \%$ (17.6 g.\%), R.B.C.s 5,540,000, P.C.V. $54 \%$.

The phonocardiogram is described under Fig. 12.

An A.P. and right lateral series of angiocardiograms were taken (Figs. 3-6). Injections of $25 \mathrm{ml}$. of $70 \%$ "pyelosil" were given and eight films exposed in five seconds on each occasion using the cassette changer

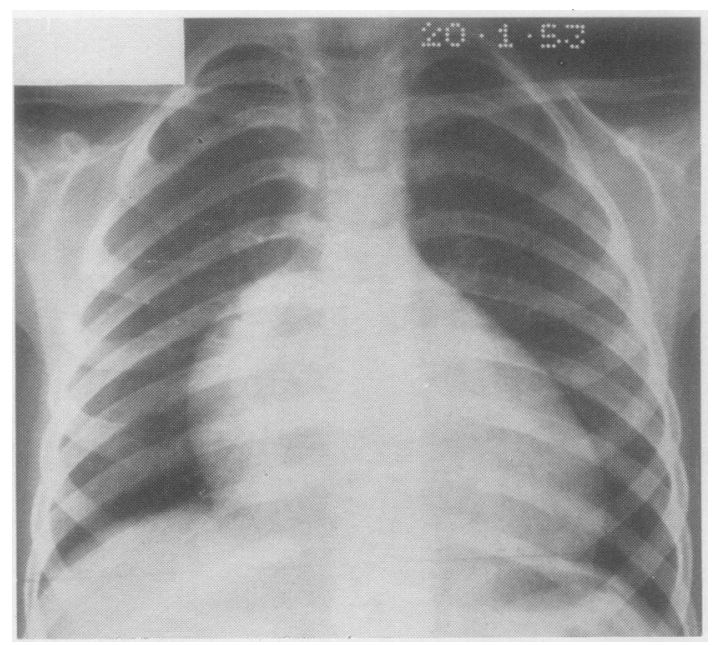

FIG. 1.-Postero-anterior chest radiograph showing typical outline and diminished lung vascular shadows. 
devised by one of us (Thursfield, 1953). In the A.P. series the dye can be seen entering the right auricle in the first film (Fig. 3) ; 0.6 seconds later the heart shadow is largely opaque and the aorta and pulmonary artery contain dye (Fig. 4). In the right lateral series dye can be seen passing from the right to the left auricle in the first film (Fig. 5). In the second film the left auricle is opaque and the pulmonary artery and aorta contain dye (Fig. 6). As

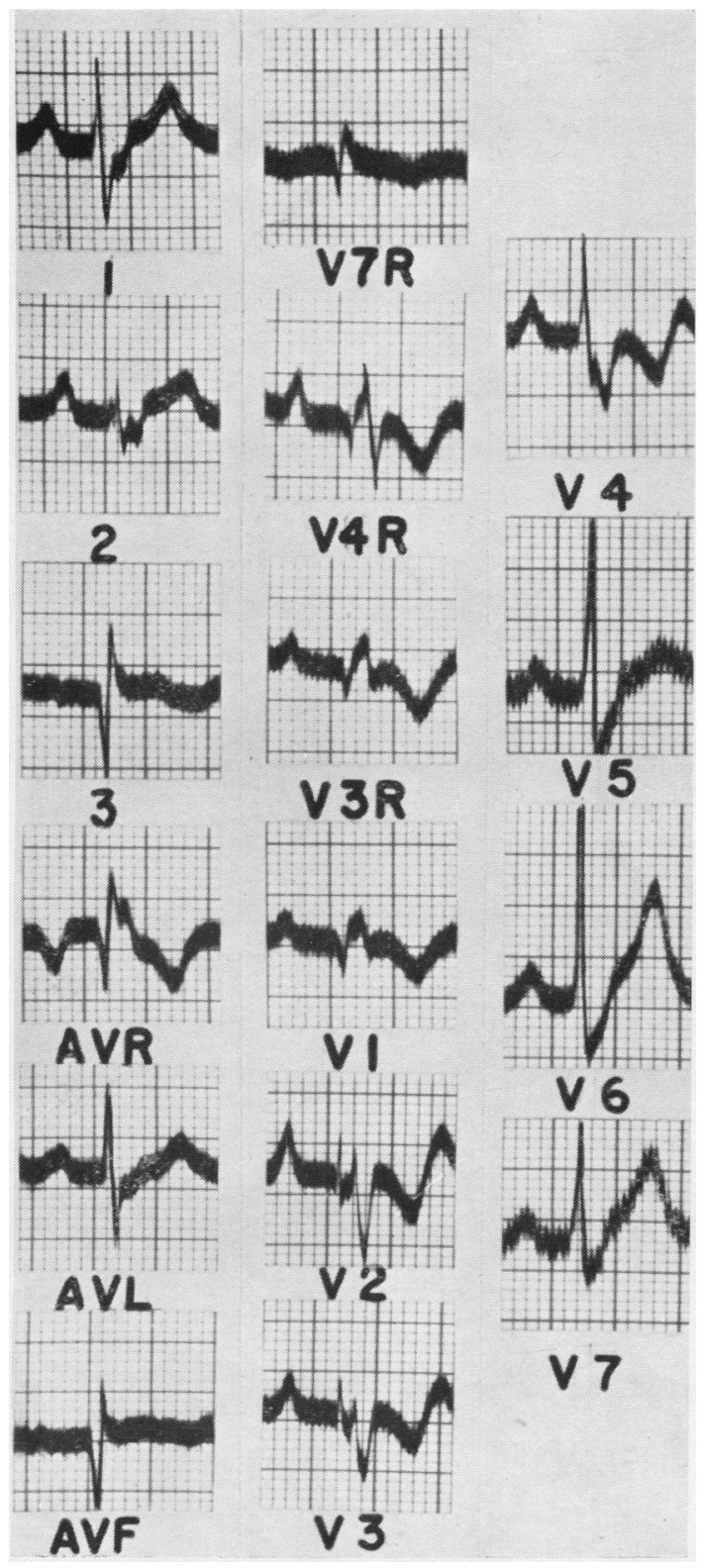

FiG. 2.-Electrocardiogram (QRS darken:d). no film was taken after five seconds delayed emptying of the right auricle could not be judged. No filling defect attributable to the tricuspid valve was seen.

The results of cardiac catheterization under rectal thiopentone are shown in Figs. 7-11 and Table II. The patient was horizontal ; zero level, sternal angle. The A.P. chest diameter was $15 \mathrm{~cm}$. The right auricle was very enlarged. The catheter repeatedly entered the right ventricle about half way up the left cardiac border. Here ventricular extrasystoles were provoked. Thus in the position shown in Fig. 9 the catheter tip was in the right auricle (Fig. 7), and in Fig. 10 it was in the right ventricle (Fig. 8). Between the two lines in Fig. 11 the catheter recorded a right ventricular pressure. Beyond the second line the catheter tip passed to the apex, on some occasions recording a right auricular, and on others a right ventricular pressure. It was therefore thought to be passing either behind, or in front, respectively, of the tricuspid sheet. The blood oxygen saturation was $55 \%$ in both the right auricle and the right ventricle.

\section{Discussion}

Ebstein first described this malformation in 1866 (Ebstein, 1866). The post-mortem descriptions of the abnormality are remarkably constant. The anterior cusp of the tricuspid valve is a sheet, frequently with fenestrated edges, attached to the inferior and septal walls of the right ventricle, dividing an enlarged right auricle posteriorly from a reduced right ventricle anteriorly. The free margin of the sheet bounds the atrio-ventricular orifice just below the pulmonary valve; the blood flow from the right auricle is diverted upwards. The wall of the right ventricle is thin. There is frequently either a patent foramen ovale or a fenestrated fossa ovalis.

Walton and Spencer (1948) reported a case and listed the findings in the 18 previously recorded cases. Table I summarizes the clinical features of the cases published since then, and Table II the catheter findings.

From Table I a characteristic picture emerges. Thus, in those patients in whom the findings are recorded the incidence of certain features is cyanosis (17 out of 21 patients) ; systolic murmur (20 out of 24$)$; diastolic murmur (13 out of 26 ) ; added sound (16 out of 19) ; cardiac outline resembling that of a pericardial effusion (19 out of 24); right bundle branch block ( 20 out of 25 ); peaked $\mathbf{P}$ waves (19 out of 25 ). Our case showed all these features except a diastolic murmur.

In nine patients a note is made of the presence or absence of pulsation to the left of the sternum in the area where a hypertrophied right ventricie may be felt. In four it was absent and in the 


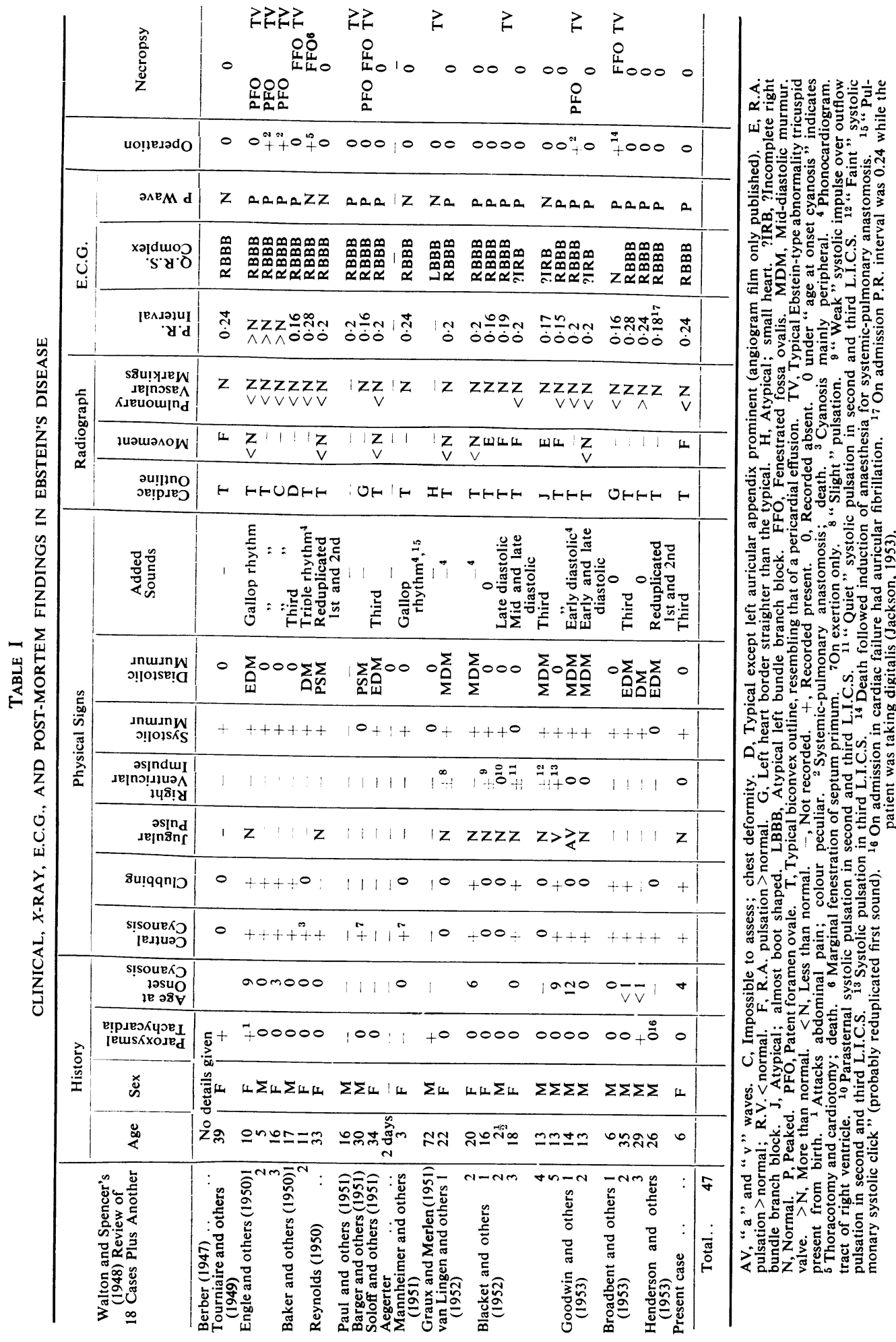




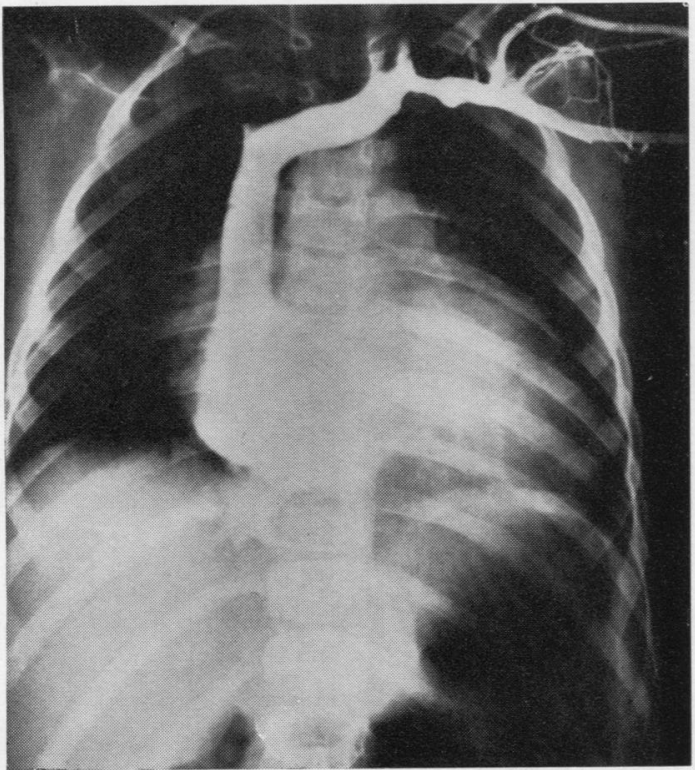

FIG. 3.-Antero-posterior angiocardiogram.

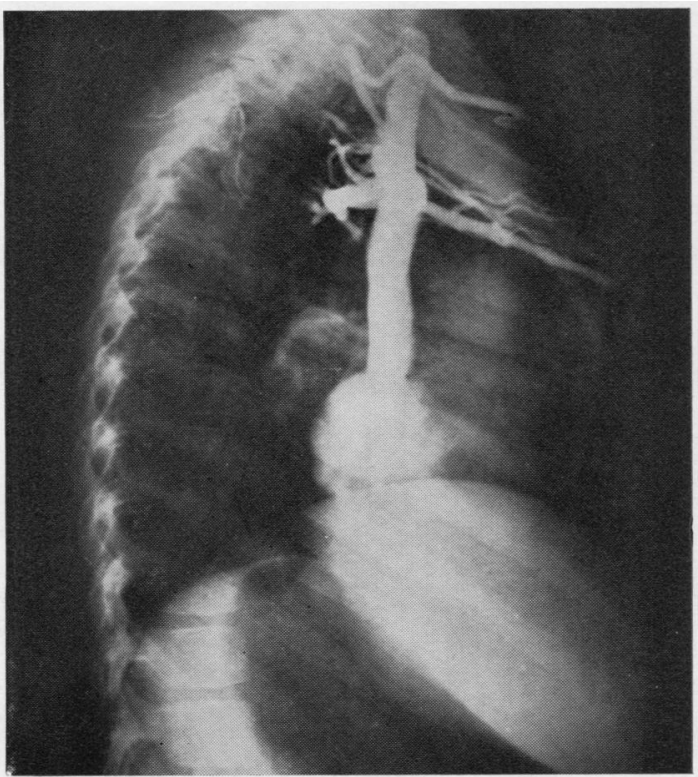

Fig. 5.-Right lateral angiocardiogram. A jet of dye can be seen passing from the right auricle to the left.

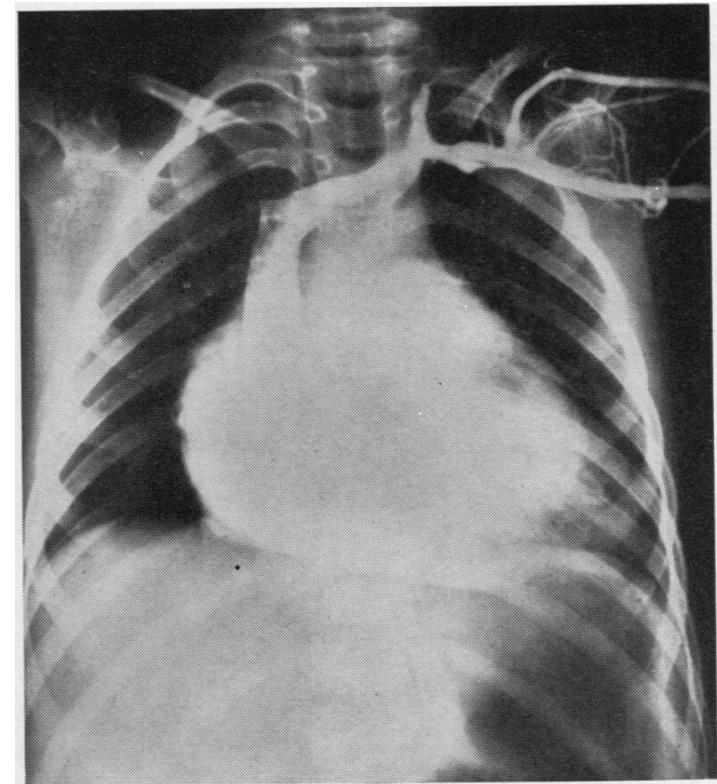

Fig. 4.-Antero-posterior angiocardiogram taken $0.6 \mathrm{sec}$. after Fig. 3.

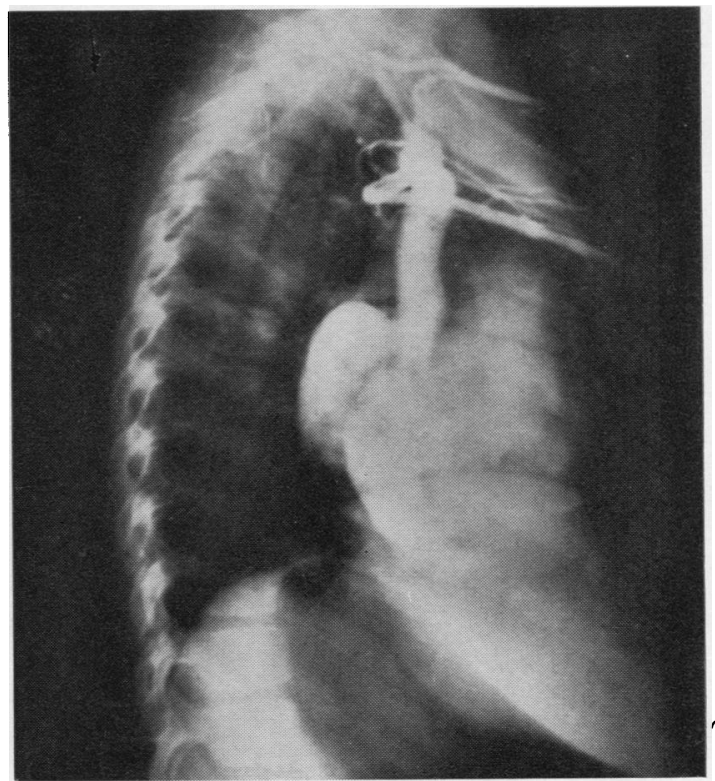

FIG. 6. - Right lateral angiocardiogram taken 0.6 sec. after Fig. 5. 


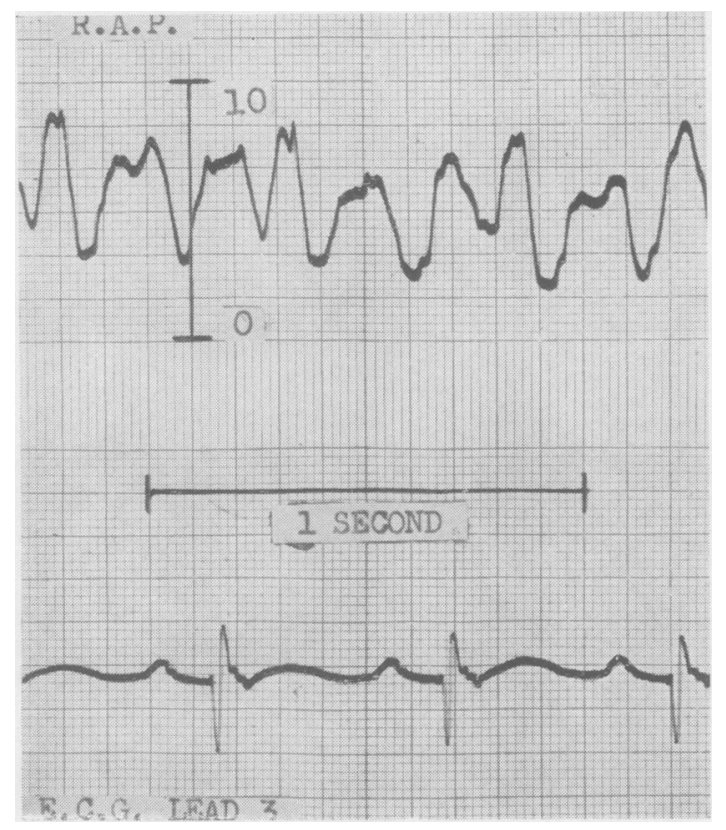

Fig. 7

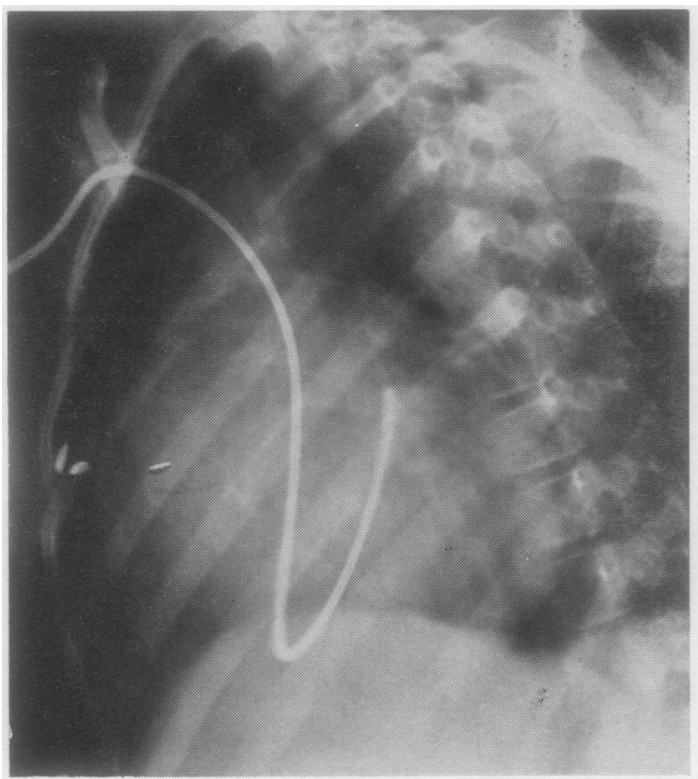

Fig. 10

Fig. 7.-Right auricular pressure (paper speed $50 \mathrm{~min} . / \mathrm{sec}$.$) .$

Fig. 8.-Right ventricular pressure. Note large " a" wave. (Paper speed $25 \mathrm{~min}$. $/ \mathrm{sec}$.)

Fig. 9.-Catheter tip recording right auricular pressure. Just above this point it entered the right ventricle (right-hand horizontal line, Fig. 11).

Fig. 10.-Left anterior obl:que radiograph: the catheter tip has just entered the right ventricle.

Fig. 11. - When the catheter tip was above the horizontal lines a right ventricular pressure was recorded. As the tip passed from the left-hand line to the apex, the catheter pressure was either right auricular or right ventricular.

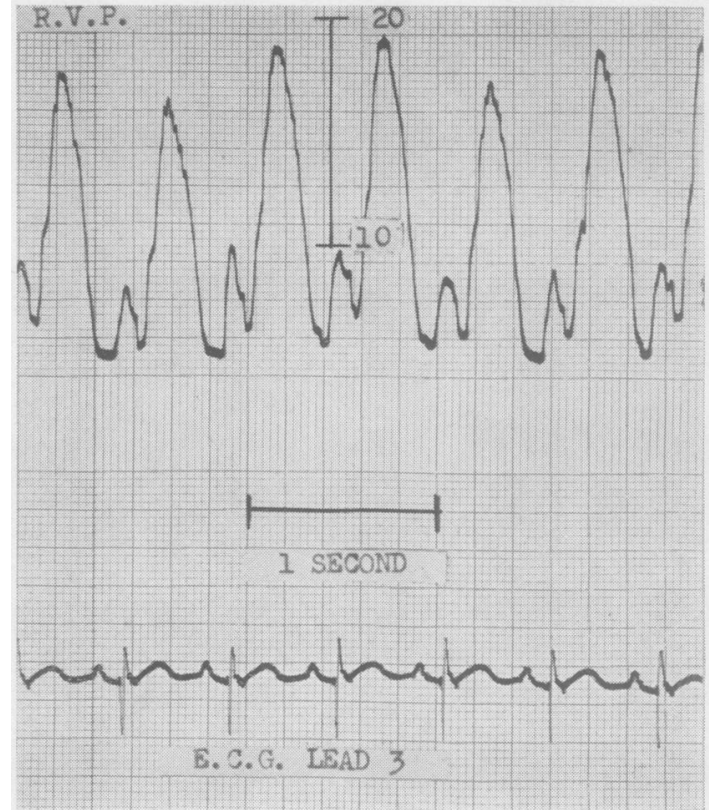

Fig. 8

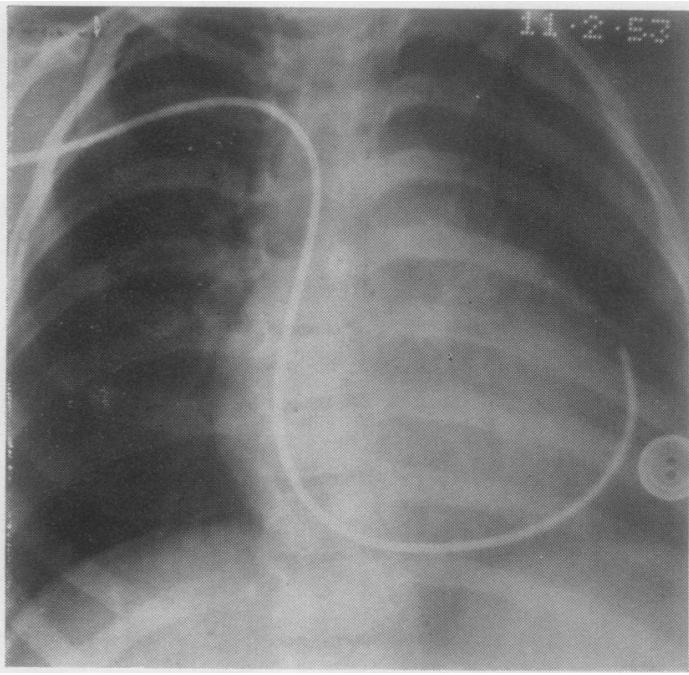

Fig. 9

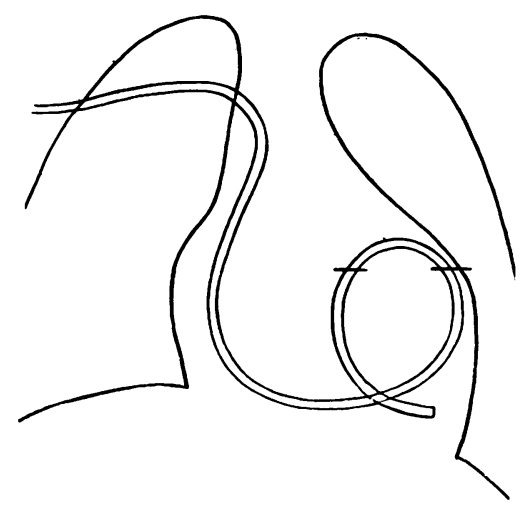

F:g 11

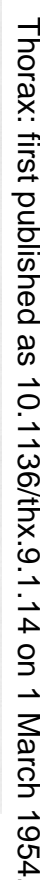

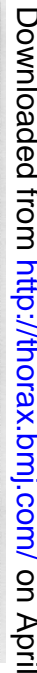

N

N

을 
TABLE II

CATHETER FINDINGS

\begin{tabular}{|c|c|c|c|c|c|c|c|c|c|}
\hline & $\begin{array}{l}\text { Reference } \\
\text { Point }\end{array}$ & 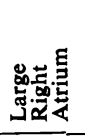 & 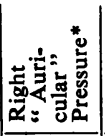 & 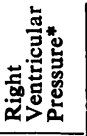 & 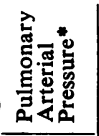 & 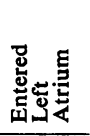 & 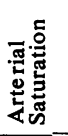 & Hazards & $\begin{array}{l}\text { Other } \\
\text { Features }\end{array}$ \\
\hline $\begin{array}{l}\text { Tourniaire and others } \\
\text { (1949) }\end{array}$ & - & - & $13 / 10$ & $16 / 13$ & $16 / 13$ & - & - & - & $\begin{array}{c}\text { Calcified } \\
\text { tricuspid }\end{array}$ \\
\hline Engle and others (1950) & - & - & 81 & $21 / 7$ & - & + & 66 & - & - \\
\hline \multirow[t]{2}{*}{$\begin{array}{l}\text { Baker and others } \\
\quad(1950)\end{array}$} & $\begin{array}{l}\text { Mid-axillary } \\
\text { line }\end{array}$ & + & 10 & - & - & + & 75 & $\begin{array}{l}\text { Popliteal e nbolism } \\
9 \text { days later }\end{array}$ & - \\
\hline & - & - & - & - & - & + & 93 & - & - \\
\hline Reynolds (1950) $\quad \ldots$ & - & - & & - & - & + & 79 & - & - \\
\hline $\begin{array}{c}\text { Mannheimer and } \\
\text { others (1951) }\end{array}$ & - & + & $4 \cdot 5 / 2 \cdot 5$ & $14 / 4 \cdot 5$ & $12 \cdot 5 / 6 \cdot 5$ & - & 81 & - & \\
\hline \multirow{2}{*}{$\begin{array}{l}\underset{(1952)}{\operatorname{van} \text { Lingen and others }} \\
1 \\
2 \\
\end{array}$} & $\begin{array}{l}5 \mathrm{~cm} \text {. post. angle } \\
\text { of Louis }\end{array}$ & - & $7 / 4$ & $22 / 4$ & $22 / 10$ & - & 87 & - & - \\
\hline & , & - & $9 \cdot 5$ & $22 / 8$ & $22 / 10$ & - & 69 & - & - \\
\hline \multirow{2}{*}{$\begin{array}{r}\text { Blacket and others } 1 \\
2\end{array}$} & - & + & $7: 1$ & $13 / 4$ & 134 & - & 97 & - & $\begin{array}{l}\text { R.V. infundibular } \\
\text { wall thin }\end{array}$ \\
\hline & - & - & - & - & - & - & - & $\begin{array}{l}\text { Cardiac arrest while } \\
\text { catheter in S.V.C. } \\
\text { Fatal }\end{array}$ & \\
\hline $\begin{array}{l}\text { Goodwin and others } \\
\text { (1953) }\end{array}$ & Sternal angle & + & 3 & - & - & - & 88 & - & - \\
\hline \multirow[t]{3}{*}{$\begin{array}{l}\text { Broadbent and } \\
\text { others (1953) }\end{array}$} & - & - & $11 / 4$ & 183 & $18 / 10$ & - & 65 & $\begin{array}{l}\text { Suprav. tachycardia } \\
\text { Controlled } \\
\text { "cedalinid" }\end{array}$ & - \\
\hline & - & - & $10 / 4$ & $19 / 4$ & $20 / 10$ & - & 89 & $-t$ & - \\
\hline & - & - & 2513 & $33 / 13$ & $34 / 22$ & - & 84 & $-\dagger$ & $\begin{array}{l}\text { C.F. Tricuspid } \\
\text { incompetence }\end{array}$ \\
\hline $\begin{array}{l}\text { Henderson and others } \\
\text { (1953) }\end{array}$ & Right atrium & + & 7 & $9-10$ & 14 & - & 91 & - & - \\
\hline Present case .. & Sternal angle & + & 84 & 184 & - & - & - & - & See text \\
\hline
\end{tabular}

* All pressures converted to $\mathrm{mm}$. $\mathrm{Hg}$.

+ Burchell, Helmholz, and Wood (1953) report that one patient with Ebstein's disease had "a cerebral embolus three weeks after the procedure [catheterization] and the onset of the [auricular] fibrillation." Another had a "transient confusional state and hemiparaesthesia lasting about twenty minutes." These two patients are not from among the three described by Broadbent and others (1953) in the same number of the Proc. Staff Meet. Mayo Clinic (Burchell, 1953).

Campbell (1953) reports one death in six patients catheterized, and reports Dr. Paul Wood's experience of one death during catheterization out of four or five. Götzsche and Falholt (i954) catheterized six without incident.

remainder slight. Special attention to this sign in future cases may show that absence of a marked pulsation is a useful sign in differentiating Ebstein's disease from forms of cyanotic congenital heart disease in which the right ventricle is hypertrophied.

Reference from the phonocardiogram (Fig. 12) and the pressure records (Figs. 7 and 8) to the electrocardiogram in each shows that the louder and later element of the first heart sound coincides with the onset of right ventricular systole. The added sound ( 3 in Fig. 12) occurs in early diastole when the right ventricular falls below the right auricular pressure. The louder element of the first sound therefore coincides with the tri- cuspid valve closing, and the added sound with the tricuspid valve opening. Right ventricular systole (Fig. 8) and left ventricular systole (carotid tracing Fig. 12) are of the same duration, but the right ventricular systolic period is delayed 0.08 sec., presumably by the right bundle branch block. Another sound (A, Fig. 12) occurs at the time of auricular contraction (Figs. 7 and 8 ).

Of the 10 patients in whom an angiocardiogram was reported, early filling of the left auricle was noted in all except that of Reynolds (1950), the first of Goodwin's (Goodwin, Wynn, and Steiner, 1953), and Henderson's (Henderson, Jackson, and Swan, 1953). Only in the first of Baker's (Baker, Brinton, and Channell, 1950) patients was there 
FIG. 12.-Synchronous phonocardiograms; high frequency (HF) from pulmonary area (PA) and medium frequency (MA) and medium frequency (MA), carotid tracing (CAR), and electrocardiogram (II). First heart sound split into several components, the first probably associated with mitral valve closure because it precedes the carotid upstroke; later components probably associated with tricuspid valve closure delayed by right bundle branch block. Long systolic murmur (SM). Second hurmur sound split into earlier aortic component, shown by synchrony with dicrotic notch of carotid tracing followed $0.07 \mathrm{sec}$. later by pulmonary component. Diastolic filling sounds accenastolic filling sounds accenated into left- and rightsided third sounds, the latter delayed by right bundle branch block, and a later auricular sound (A). (Time marker 0.2 sec and 0.04 marker, 0.2 sec. and 0.04 sec.) (The phonocardiogram and report were kindly provided by Dr. A.
Leatham.)

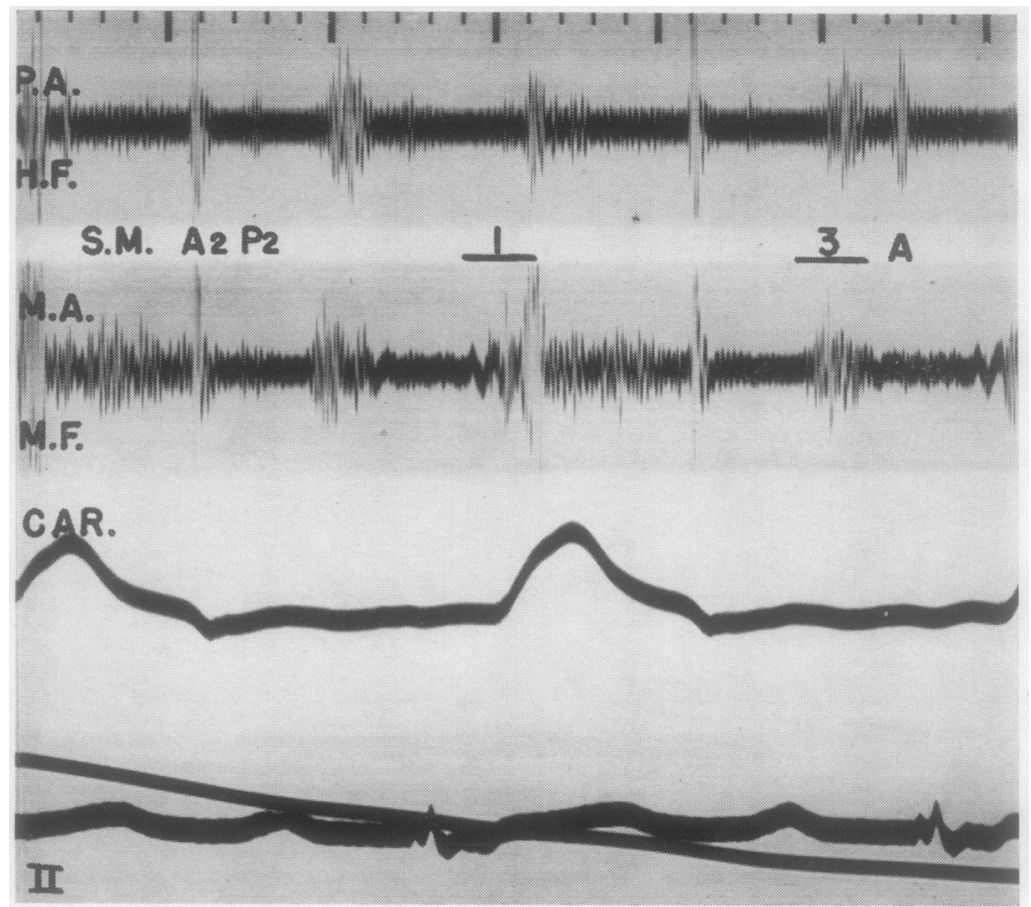

no delay in the emptying of the right auricle. A filling defect thought to be due to the misplaced tricuspid valve was described by Soloff, Stauffer, and Zatuchni (1951) and Goodwin, Wynn, and Steiner (1953).

At catheterization the pressures recorded were similar to the reported cases in Table II (with the exception of Broadbent's (Broadbent, Wood, Burchell, and Parker, 1953) case 3 ; this patient was in cardiac failure). The right auricular pressure was raised and the right ventricular pressure normal. In the absence of tricuspid stenosis this combination does not occur in any other form of congenital cyanotic heart disease. The high right auricular pressure is an indication of the inefficiency of the right ventricle, and is responsible for the right-to-left shunt. In none of the recorded cases has there been evidence of tricuspid stenosis as judged by a diastolic pressure difference across the valve. Only in the case of Broadbent's which was in cardiac failure was there evidence of tricuspid incompetence, namely a large " $V$ " wave in the right auricular tracing. That there is a danger in catheterizing these patients is shown by the complications reported (Table II). However, anastomotic operations have been invariably lethal in the reported cases (Table I) so that where there is doubt catheterization is justifiable.

\section{Summary}

A case of Ebstein's disease is described. A finding at cardiac catheterization which we consider as diagnostic is recorded. Cases published since 1948 are summarized. The possibility of making a clinical diagnosis and the danger of operation are stressed.

The patient was under the care of Dr. J. Forest Smith, who kindly gave permission for publication. We would also like to thank Miss D. Holdway and Mrs. N. Thompson for secretarial, and Mr. J. O. L. Wrigley and Mr. K. G. Moreman for technical and photographic, assistance respectively.

\section{REFERENCES}

Aegerter, E. E., quoted Soloff, L. A., et al. (1951). Aegerter, E. E., quoted Soloff, L. A., et al. (1951).
Baker, C., Brinton, W. D., and Channell, G. D. (1950). Guy's Hosp.
Rep., 99, 247.

Barger, J. D., Henderson, C. E., and Edwards, J. E. (1951). Amer. J. clin. Path., 21, 576.

Berber, S. G. (1947). Cuore e Circol., 31, 54.

Blacket, R. B., Sinclair-Smith, B. C., Palmer, A. J., Halliday, J. H., and Maddox, J. K. (1952). Aust. Ann. Med., 1, 26.

Broadbent, J. C., Wood, E. H., Burchell, H. B., and Parker, R. L. (1953). Proc. Mayo Clin., $28,79$.

Burchell, H. B. (1953). Personal communication.

- Helmholz, LH. F., and Wood, E. H. (1953). Proc. Mayo Clin., 28, 50. 
Campbell, M. (1953). Brit. Heart J., 15, 363. Editorial note.

Ebstein, W. (1866). Arch. Anat. Physiol., Lpz., p. 238.

Engle, M. A., Payne, T. P. B., Bruins, C., and Taussig, H. B. (1950). Circulation, 1, 1246.

Goodwin, J. F., Wynn,'A., and Steiner, R. E. (1953). Amer. Heart J., 45, 144.

Götzsche, H., and Falholt, W. (1954). Ibid., in the press.

Graux, P., and Merlen, J.-F. (1951). Arch. Mal. Coeur, 44, 263.

Henderson, C. B., Jackson, F., and Swan, W. G. A. (1953). Brit. Heart J., 15, 360.

Jackson, F. (1953). Personal communication.

Lingen, B. van, McGregor, M., Kaye, J., Meyer, M. J., Jacobs, H. D., Braudo, J. L., Bothwell, T. H., and Elliott, G. A. (1952). Amer. Heart J., 43, 77 .
Mannheimer, E., Bengtsson, E., Krämer, R., Warth, J., Wade, G. Wegelius, C., and Winberg, J. (1951). Proc. of the Tenth Northern Paediatric Congress, Stockholm, 1951. Acta paediat., Uppsala, 40, Suppl. 83, p. 194. (Unpublished data kindly provided by Dr. Mannheimer.)

Paul, O., Myers, G. S., and Campbell, J. A. (1951). Circulation, 3, 564

Reynolds, G. (1950). Guy's Hosp. Rep., 99, 276.

Soloff, L. A., Stauffer, H. M., and Zatuchni, J. (1951). Amer. J. med. Sci., 222, 554.

Thursfield, W. R. R. (1953), Brit. J. Radiol., 26, 383.

Tourniaire, A., Deyrieux, F., and Tartulier, M. (1949). Arch. Mal. Coeur, 42, 1211.

Walton, K., and Spencer,A. G. (1948). J. Path. Bact., 60, 387. 